\title{
Preface to Special Issue on the National Report to the IUGG Centennial by CNC-IAMAS (2011-2018)
}

https://doi.org/10.1007/s00376-019-9005-1

The 27th General Assembly of the International Union of Geodesy and Geophysics (IUGG), which also marks the 100th anniversary of IUGG, will be held during 8-18 July 2019 in Montréal, Canada. The Chinese National Committee (CNC) for the International Association of Meteorology and Atmospheric Sciences (IAMAS) has a more than 30-year tradition of submitting national reports to the IUGG General Assembly every four years. Since 2004, CNC-IAMAS has published its progress report as a special issue in Advances in Atmospheric Sciences. Three special issues comprising invited reviews written by leading Chinese scientists, published in 2004, 2007 and 2012 respectively, have received wide attention and are highly cited.

To prepare a progress report for the upcoming IUGG General Assembly in 2019, which happens to be centennial anniversary of IUGG, we invited some senior scientists from China to review some advances and achievements in meteorology and atmospheric sciences in China, mainly for the period 2011-2018, and hence form a special issue. The special issue includes nine review articles, which cover monsoon (Chen et al., 2019), climate and climate change (Li et al., 2019; Huang et al., 2019), numerical atmospheric modeling (Yu et al., 2019), aerosol physical properties (Zhao et al., 2019a), chemistry-climate interaction (Fu et al., 2019), atmospheric electricity (Qie and Zhang, 2019), weather radar (Zhao et al., 2019b), and meteorological satellites (Zhang et al., 2019). For various reasons, progress in many other atmospheric scientific topics has not been collected in this report. Nonetheless, this national report shows what the Chinese community has contributed in the past eight years to the international scientific community in meteorology and atmospheric sciences. We thank every scientist involved in compiling this national report.

\author{
Chinese National Committee for IAMAS \\ Daren LÜ, Chairman \\ Jianchun BIAN, General Secretary
}

\section{REFERENCES}

Chen, W., L. Wang, J. Feng, Z. P. Wen, T. J, Ma, X. Q. Yang, and C. H. Wang, 2019: Recent progress in studies of the variabilities mechanisms of the East Asian monsoon in a changing climate. Adv. Atmos. Sci., 36(9), 887-901, https://doi.org/10.1007/s00376019-8230-y.

Fu, Y., H. Liao, and Y. Yang, 2019: Interannual and decadal changes in tropospheric ozone in China and the associated chemistry-climate interactions: A review. Adv. Atmos. Sci., 36(9), 975-993, https://doi.org/10.1007/s00376-019-8216-9.

Huang, J. P., J. R. Ma, X. D. Guan, Y. Li, and Y. L. He, 2019: Progress in semi-arid climate change studies in China. Adv. Atmos. Sci., 36(9), 922-937, https://doi.org/10.1007/s00376-018-8200-9.

Li, J. P., F. Zheng, C. Sun, J. Feng, and J. Wang, 2019: Pathways of influence of the Northern Hemisphere mid-high latitudes on East Asian climate: A review. Adv. Atmos. Sci., 36(9), 902-921, https://doi.org/10.1007/s00376-019-8236-5.

Qie, X. S., and Y. J, Zhang, 2019: A review of atmospheric electricity research in China from 2011 to 2018. Adv. Atmos. Sci., 36(9), 994-1014, https://doi.org/10.1007/s00376-019-8195-x.

Yu, R. C., Y. Zhang, J. J. Wang, J. Li, H. M. Chen, J. D. Gong, and J. Chen, 2019: Recent progress in numerical atmospheric modeling in China. Adv. Atmos. Sci., 36(9), 938-960, https://doi.org/10.1007/s00376-019-8203-1.

Zhang, P., and Coauthors, 2019: Latest progress of the Chinese meteorological satellite program and core data processing technologies. Adv. Atmos. Sci., 36(9), 1027-1045, https://doi.org/10.1007/s00376-019-8215-x.

Zhao C. S., Y. L. Yu, Y. Kuang, J. C. Tao, and G. Zhao, 2019: Recent progress of aerosol light-scattering enhancement factor studies in China. Adv. Atmos. Sci., 36(9), 1015-1026, https://doi.org/10.1007/s00376-019-8248-1.

Zhao, K., and Coauthors, 2019: Recent progress in dual-polarization radar research and applications in China. Adv. Atmos. Sci., 36(9), 961-974, https://doi.org/10.1007/s00376-019-9057-2. 